\title{
Growth Control of Lung Cancer by Interruption of 5-Lipoxygenase-mediated Growth Factor Signaling
}

\author{
Ingalill M. Avis, ${ }^{\star}$ Marti Jett, ${ }^{\ddagger}$ Thomas Boyle, ${ }^{\ddagger}$ Michele D. Vos, ${ }^{\star}$ Terry Moody, ${ }^{\star}$ Anthony M. Treston, ${ }^{\star}$ Alfredo Martínez, ${ }^{\star}$ and \\ James L. Mulshine* \\ *National Cancer Institute, Biomarkers and Prevention Research Branch, Rockville, Maryland 20850-3300; and ${ }^{*}$ Walter Reed Army \\ Institute of Research, Division of Pathology, Washington DC 20307-5100
}

\begin{abstract}
Signal transduction pathways shared by different autocrine growth factors may provide an efficient approach to accomplish clinically significant control of lung cancer growth. In this study, we demonstrate that two autocrine growth factors activate 5-lipoxygenase action of the arachidonic acid metabolic pathway in lung cancer cell lines. Both growth factors increased the production of 5(S)-hydrooxyeicosa6E,8Z,11Z,14Z-tetraenoic acid (5-HETE), a major early 5-lipoxygenase metabolic product. Exogenously added 5-HETE stimulated lung cancer cell growth in vitro. Inhibition of 5-lipoxygenase metabolism by selective antagonists resulted in significant growth reduction for a number of lung cancer cell lines. Primary clinical specimens and lung cancer cell lines express the message for the 5-lipoxygenase enzymes responsible for the generation of active metabolites. In vivo evaluation demonstrated that interruption of 5-lipoxygenase signaling resulted in enhanced levels of programmed cell death. These findings demonstrate that 5-lipoxygenase activation is involved with growth factor-mediated growth stimulation for lung cancer cell lines. Pharmacological intervention with lipoxygenase inhibitors may be an important new clinical strategy to regulate growth factor-dependent stages of lung carcinogenesis. ( $J$. Clin. Invest. 1996. 97:806-813.) Key words: lipoxygenase pathway $\bullet$ 5-HETE $\bullet$ signal transduction $\bullet$ growth inhibition -apoptosis
\end{abstract}

\section{Introduction}

The high mortality rate of lung cancer has not been ameliorated by current therapeutic efforts $(1,2)$. Therefore new strategies for the successful management of this disease are essential. Lung cancer tumors and cell lines synthesize growth factor(s) including gastrin-releasing peptide (GRP) ${ }^{1}$ and IGF, which play autocrine stimulatory roles in lung cancer (3-6). Since the effect of autocrine growth factors can be blocked by

The views of the authors do not purport to reflect the position of the Department of the Army or the Department of Defense (Para 4-3) AR 360-5.

Address correspondence to James L. Mulshine, BPRB, NCI, 9610 Medical Center Drive, Room 300, Rockville, MD 20850-3300. Phone: 301-402-3128; FAX: 301-402-4422; E-mail: mulshinej@bprb.nci.nih.gov

Received for publication 14 September 1995 and accepted in revised form 20 November 1995.

The Journal of Clinical Investigation

Volume 97, Number 3, February 1996, 806-813 specific antagonists such as mAbs, we have previously proposed a chemoprevention strategy to prevent clonal expansion of early cancer cells by neutralizing autocrine growth factor effects (7). The autocrine hypothesis suggests that the production and response to growth factors by tumor cells may account for the characteristic loss of growth regulation by cancer cells (8). The clonal expansion of an early transformed epithelial cell and the progression of an advanced cancer cell to metastatic disease are both mediated by chronic growth factor stimulation. The important autocrine growth factors, IGF and GRP provide attractive targets for developing treatment and chemopreventive strategies.

Early signal transduction events for lung cancer have been reported to involve rapid production of inositol 1,4,5-triphosphate, mobilization of $\mathrm{Ca}^{2+}$, and activation of phospholipase $\mathrm{C}$ $(9,10)$. Others have reported that the signaling pathway for neuropeptide-induced mitogenesis activates the release of AA in the Swiss 3 T3 model (11). However, to date the AA signaling pathway is less clearly defined in lung cancer models (12, 13). Activation of AA metabolism is initiated by the release of AA from the phospholipid pool by the enzyme phospholipase A2 (14). The released AA can be metabolized by the cyclooxygenase pathway where AA is rapidly transformed to prostaglandins, and subsequent metabolites (15). Compounds which preferentially inhibit AA metabolism to prostaglandins, such as aspirin, are emerging as potentially important tools for cancer management (16). The other AA metabolic route is the lipoxygenase pathway, where AA is converted by fatty acid lipoxygenases into hydroperoxy derivatives and eventually to hydroxy compounds and their metabolites or to leukotrienes (Fig. 1). A number of pharmacologic antagonists for this pathway are being used in specific clinical settings (17). Inhibitors of 5-lipoxygenase (5-LO) metabolism have shown promise in the treatment of asthma and shock with limited side effects in preclinical and clinical trials $(18,19)$.

While the cyclooxygenase pathway may be important for regulating colon cancer growth, our results suggests at least a comparable role for the 5-LO pathway for other epithelial cancers. In this study, we demonstrate that the 5-LO branch of the AA signaling pathway for lung cancer cell lines was activated after stimulation with two known autocrine growth factors. Inhibitors of AA metabolism can antagonize the biochemical effects of growth factors and inhibit cell growth. Furthermore,

1. Abbreviations used in this paper: 5-LO, 5-lipoxygenase; 5-HETE, 5(S)-hydrooxyeicosa-6E,8Z,11Z,14Z-tetraenoic acid; AA861, 2(12hydroxydodeca-5-10-dinyl)-3,5,6-trimethyl-1-4-benzoquinone inhibitor; ASA, acetylsalicylic acid; FLAP, 5-LO-activation protein; GRP, gastrin-releasing peptide; NDGA, nordihydroguaiaretic acid; NSCLC, non-SCLC; RT, reverse transcriptase; SCLC, small cell lung cancer cell. 


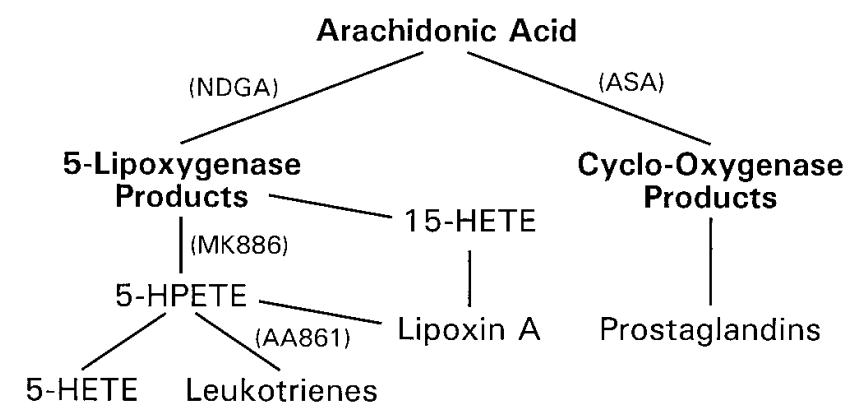

Figure 1. Schematic outline of AA metabolism. The released arachidonic acid is metabolized either by cyclooxygenase pathway (right), or the lipoxygenase pathway (left). The proposed site of action for the inhibitors used in the study is shown in parenthesis.

when 5-LO antagonists were used a greater antiproliferative effect was observed than what was achievable with a cyclooxygenase inhibitor. The critical role of this growth factor signaling circuit may be to permit cells to cycle through apoptotic growth control as recently discussed (20), and 5-LO may be an important mediator in this process. Our data suggests that 5-LO antagonists may provide a strategic tool in neutralizing the effects of specific growth factors which are clinically significant in respiratory carcinogenesis.

\section{Methods}

Cell lines. Cell lines used in the study were established at the National Cancer Institute-Naval Medical Oncology Branch, Bethesda, MD and maintained in RPMI 1640, supplemented with 5\% FBS, penicillin $(50 \mathrm{U} / \mathrm{ml})$ and streptomycin $(50 \mathrm{mg} / \mathrm{ml})$ (Gibco BRL, Grand Island, NY), in a humidified atmosphere of $95 \%$ air and $5 \% \mathrm{CO}_{2}$ atmosphere at $37^{\circ} \mathrm{C}$. The cell lines were free of mycoplasma contamination.

HPLC characterization. Briefly, $\left[{ }^{3} \mathrm{H}\right] \mathrm{AA} \quad\left(100 \mathrm{mCi} / 150 \quad \mathrm{~cm}^{2}\right.$ flask) was incorporated into cells overnight. The culture fluid was removed and the cells washed twice with PBS. They were resuspended in a balanced salt buffer (21) and were then exposed to various agonists, and the reaction was stopped by acidification with $0.1 \mathrm{M}$ formic acid, $10 \mathrm{mM}$ butylated hydroxytoluene in methanol. The cells were disrupted, and cellular debris removed by centrifugation. The supernatant was diluted fivefold, an internal standard was added, and the arachidonate metabolites were extracted onto disposable C-18 cartridges. The various metabolites were separated by RP-HPLC using a Beckman "Gold" HPLC chromatographic system with a Beckman Ultrasphere $5 \mathrm{~mm}$ analytical ODS $(4.6 \times 250 \mathrm{~mm})$ column $($ Beckman Instruments Inc., Irvine, CA) and detected using an on-line radioactivity detector (Packard Radiomatic, Chicago, IL).

The inhibition studies were performed by incubating the small cell lung cancer cell line (SCLC) NCI-H209 cells with [ $\left.{ }^{3} \mathrm{H}\right] \mathrm{AA}$; the inhibitors were then incubated with the cultures for $30 \mathrm{~min}$ before addition of the agonist. Growth factors or buffer was added to each pair of samples (control, AA861, acetylsalicylic acid [ASA]). Kinetic determinations (30, 60, $90 \mathrm{~s}$ and 2, 3, 6, 12, $30 \mathrm{~min})$ were made. AA metabolites were extracted, separated, and quantitated as previously published and described above (15).

Inhibitors. ASA was purchased from Sigma Chemicals (St. Louis, MO). Nordihydroguaiaretic acid (NDGA) and AA861 were obtained from BIOMOL Research Laboratories (Plymouth Meeting, PA). 5-lipoxygenase-activating protein (FLAP) inhibitor, MK 886 (22), was a kind gift from Merck Frosst Centre for Therapeutic Research (Pointe Claire-Dorval, Canada).

Growth studies. We used a modification (CellTiter 96 ${ }^{\mathrm{TM}}$; Pro- mega Corp., Madison, WI) of the semiautomated MTT colorimetric assay (23) which quantitates cell numbers based on the reduction of a tetrazolium compound by tumor cells to a colored formazan end product, which is quantitated by measuring the change in optical density $(570 \mathrm{~nm})$ compared with a control. Seeding densities were $1-2 \times$ $10^{4}$ cells/well, and cells were grown for $5 \mathrm{~d}$. Experiments were repeated at least three times.

$m R N A$ expression. Reverse transcriptase (RT)-PCRs were performed using $100 \mathrm{ng}$ poly (A) ${ }^{+}$RNA (Gibco BRL). First-strand cDNA, prepared using random hexamers, was PCR-amplified using oligonucleotides derived from cDNA sequences of 5-LO and FLAP and selected using Lasergene Software by DNASTAR (Madison, WI). Forward (F) and reversed (R) primers used to detect 5-LO and FLAP cDNAs in the amplification were: 5LO-F (5'-CCCGGGGCATGGAGAGAGCA-3')，5LO-R (5'-GCGGTCGGGCAGCGTGTC-3'), FLAP-F (5'-GCTGCGTTTGCTGGACTGATGTA-3'), FLAP-R (5'-TAGAGGGGAGATGGTGGTGGAGAT-3'). PCR amplification was performed for 35 cycles with $94^{\circ} \mathrm{C}$ denaturation for $30 \mathrm{~s}, 60^{\circ} \mathrm{C}$ annealing for $15 \mathrm{~s}$, and $72^{\circ} \mathrm{C}$ extension for $1 \mathrm{~min}$. RT-PCR products were resolved in a $1.3 \%$ agarose gel run in $1 \times$ TBE buffer and confirmed by Southern blotting onto nitrocellulose and hybridization to radiolabeled internal primer probes as described by established methods (24). Amplification products for both 5-LO and FLAP were of the expected size (data not shown) as determined by ethidium bromide staining.

In situ RT-PCR was performed following established methods (25) with the same primers used above. Briefly, after proteinase K digestion the sections were subjected to reverse transcription with the same kit used for regular RT-PCR. The PCR mixture (Perkin Elmer Cetus, Norwalk, CT) contained $2.5 \mathrm{mM} \mathrm{MgCl}, 2.5 \mathrm{U} / 100 \mathrm{ml}$ Taq DNA polymerase, $200 \mathrm{mM}$ dNTPs, $100 \mathrm{mM}$ digoxigenin-11-dUTP (Boehringer Mannheim Biochemicals, Indianapolis, IN), $1 \mathrm{ng} / \mathrm{ml}$ primers, $50 \mathrm{mM} \mathrm{KCl}, 10 \mathrm{mM}$ Tris- $\mathrm{HCl}, \mathrm{pH}$ 8.3. To achieve a synchronized "hot start," Taq polymerase was blocked with TaqStart antibody (Clontech, Palo Alto, CA). The incorporated digoxigenin was localized with the Digoxigenin Detection Kit (Boehringer Mannheim Biochemicals).

Athymic nu/nu mouse experiments. NCI-H209 tumor cells $\left(10^{7} /\right.$ mouse) were subcutaneously injected into the flanks of athymic nu/ $\mathrm{nu} \mathrm{Balb} / \mathrm{c}$ mice, and a palpable mass formed after $7 \mathrm{~d}$. Treatment began on day 7 and consisted of two groups. The mice were given either $0.1 \%$ NDGA in their drinking water for $4.5 \mathrm{wk}$ or PBS (placebo group). Tumors were measured twice a week. For the apoptosis experiments, tumors from four mice in each of the NDGA and placebo group were killed at the conclusion of the study, and the flank tumors were harvested.

Apoptosis analysis. The tumors were fixed in $10 \%$ buffered formalin for $24 \mathrm{~h}$ and paraffin embedded. The tissue sections were analyzed for the presence of apoptosis-induced nucleosomes using the ApopTag in situ apoptosis detection kit (Oncor Inc., Gaithersburg, $\mathrm{MD})$. The number of apoptotic cells was counted in 10 microscopic fields $(\times 40)$ of each case.

Statistics. Significance of difference between samples was determined using Student's paired $t$ test. $P<0.05$ was regarded as significant.

\section{Results}

Kinetic studies of AA metabolism. For an SCLC cell line, we analyzed intracellular AA signaling after exposure to two growth factors. Kinetic studies were performed, and samples analyzed using a previously reported HPLC chromatographic procedure (15). The earliest metabolite produced by IGF-I (30 s) was 5(S)-hydrooxyeicosa-6E,8Z,11Z,14Z-tetraenoic acid (5-HETE). GRP also stimulated production of 5-HETE, although its production was slightly delayed (90 s) compared to IGF-I (Fig. $2 A$ ). IGF-I-stimulated 5-HETE production was 


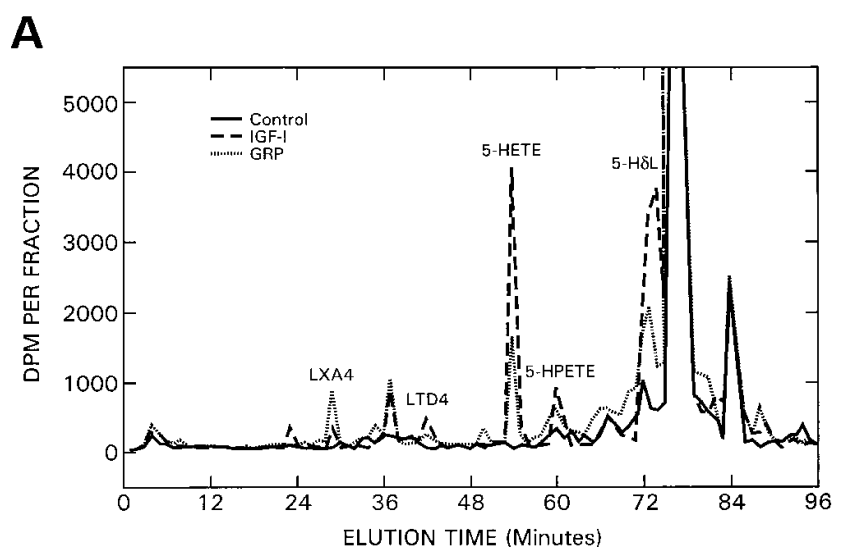

B

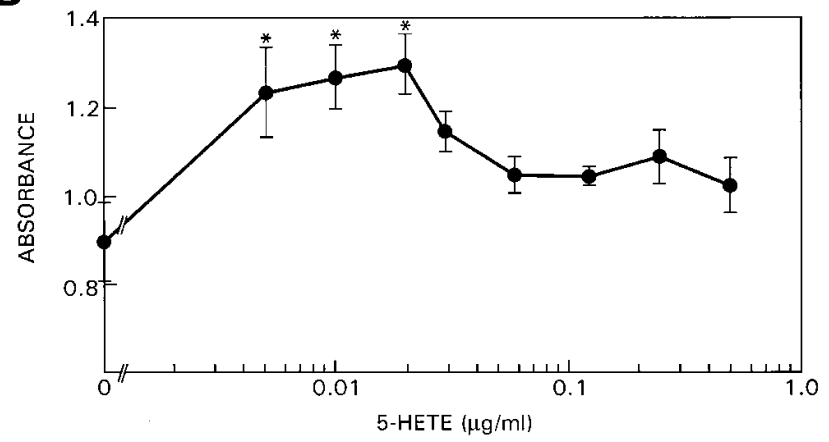

Figure 2. HPLC characterization of AA metabolism. $(A)$ The result is presented as an elution profile after exposure of NCI-H209 cells to IGF-I (30 s) and GRP (90 s). Cell line NCI-H209 was exposed to $2 \mathrm{ng} /$ $\mathrm{ml}$ IGF-I or to $5 \mathrm{ng} / \mathrm{ml} \mathrm{GRP}$; the samples were then analyzed using a previously reported HPLC chromatographic procedure (15). (B) Effect of exogenous addition of the AA metabolite 5-HETE on the proliferation of NCI H-209 cells. A representative experiment is shown, and the result is expressed as mean $\mathrm{OD} \pm \mathrm{SD}$ of eight data points. Asterisks indicate significant stimulation as compared to vehicle control $(P<0.05)$. Maximal stimulation was observed at $0.02 \mu \mathrm{g} / \mathrm{ml}$ 5-HETE.

maximal from 2 to $6 \mathrm{~min}$; by $12 \mathrm{~min}$ its level, although decreased, was 1.3-fold higher than control (however, alternate 5-LO and downstream metabolites of 5-HETE were also elevated at 12 and $20 \mathrm{~min}$ ). The 5-HETE metabolite showed characteristic ultraviolet absorbance maxima by dual wavelength at 216/235 nm, and 5-HETE was also identified by a specific RIA (data not shown). The involvement of 5-HETE in the growth stimulation was confirmed by the exogenous addition of 5-HETE to tumor cells (Fig. 2 B). A significant, reproducible, dose-dependent increase in cell growth for H209 was observed with the exogenous addition of 5-HETE, as measured by a modified MTT growth assay.

Inhibition of $A A$ metabolism. The schema in Fig. 1 outlines where the inhibitors used in this study act on the metabolism of AA. The arachidonate metabolites generated by IGF-I or GRP stimulation of NCI-H209 were studied in the presence and absence of a 5-LO inhibitor, 2-(12-hydroxydodeca-5-10dinyl)-3,5,6-trimethyl-1-4-benzoquinone inhibitor (AA861), and the cyclooxygenase inhibitor, ASA. Fig. 3 shows the response of 16 arachidonate metabolites subsequent to IGF-I stimulation, with or without preexposure to AA861 or ASA. Major products which showed dynamic responses after exposure to growth factors are presented.
Fig. $3 A$ shows that the levels of 5-LO-generated metabolites increased when stimulated with IGF-I. The most significant changes were in the production of 5-HETE, LTD4, and AA itself. 5-HETE and LTD4 were maximally stimulated, $>$ threefold over control levels, at time points within 2 min after addition of IGF-I. Under our experimental conditions neither LTB4 nor LTD4 affected proliferation rates in NCI-H209 cells (data not shown) in contrast to our results with 5-HETE (Fig. $2 B$ ). AA itself was increased approximately twofold by IGF-I. Other metabolites such as prostanoids, lipoxin A4, 12-, and 15-HETE were also increased to lesser degrees. In the presence of IGF-I, 5-LO inhibitors reversed these effects with consistent inhibition of 5-HETE, LTD4 and AA production. Representative data shown for AA861 demonstrate this pattern. Upon preincubation with AA861 alone, 5-LO metabolites remained approximately at control levels as expected (Fig. $3 \mathrm{~A}$ ), while a prostanoid and 15-HETE were elevated above controls (Fig. $3 B$ ).

In contrast, addition of AA861 followed by IGF-I stimulation resulted in marked elevation of 5-HPETE, 5-HETE $\delta$-lactone, and 15-HETE. The leukotrienes were produced at approximately control levels except for LTB4, a minor product. The radioactivity associated with the various metabolites in control cultures (after subtraction of background) fell into three ranges: cpm of 700-1,300 (prostanoids, LTB4, and its oxidation products, LXA4, and LTC4), 3,000-7,000 (LTD4, LTE4, 5-,12-, and 15-HETEs, and HPETEs, 15 HETE methyl ester, and 5-HETE $\delta$-lactone), and > 20,000 (AA). We have seen consistently that changing the culture fluid to the reaction buffer stimulates a minor onset of AA metabolism. Growth factors, such as IGF-I and GRP, stimulate multiple-fold production of certain of these metabolites as is shown in Fig. 3. These results suggest that AA861 may be stabilizing the peroxide (5-HPETE) or may exert its blocking effect on the leukotriene branch of the pathway rather than on the formation of the parent 5-eicosanoid derivative, as has been previously suggested (26). The metabolite 5-HETE $\delta$-lactone can be produced enzymatically from either 5-HPETE or 5-HETE. These data suggest that in the presence of AA861, 5-HPETE was converted directly to the lactone.

In comparison, pretreatment of the cells with ASA showed the expected blockage in the appearance of prostanoids. In general, pretreatment with ASA alone, although it elevated several metabolites, did not show significant increase in alternate pathways. Agonist stimulation (IGF-I) in the presence of ASA showed a 5.8-fold increase in LTD4 and a significant increase in the compounds 5-HPETE, AA, and 15-HPETE.

Regulation of cell growth. The kinetics of production of metabolites, and the ability of 5-HETE to stimulate proliferation, encouraged us to focus on the role of these pathways in regulation of cell growth. To determine the biological effect of AA metabolic pathway inhibitors on lung cancer cell line proliferation, we evaluated the effect of different inhibitors on the growth of a range of lung cancer cell lines including both SCLC and non-SCLC (NSCLC) cell lines. Representative growth curves for three different cell lines assayed in the presence of the cyclooxygenase inhibitor ASA is shown in Fig. $4 A$. In general ASA had a better growth inhibitory effect on the NSCLC cell lines than the SCLC cell lines, only NCI-H209 was inhibited by $>30 \%$. (Table I). The limited inhibitory effect of ASA in vitro on the SCLC cell lines correlates with our observations that arachidonic metabolism was not greatly altered by 

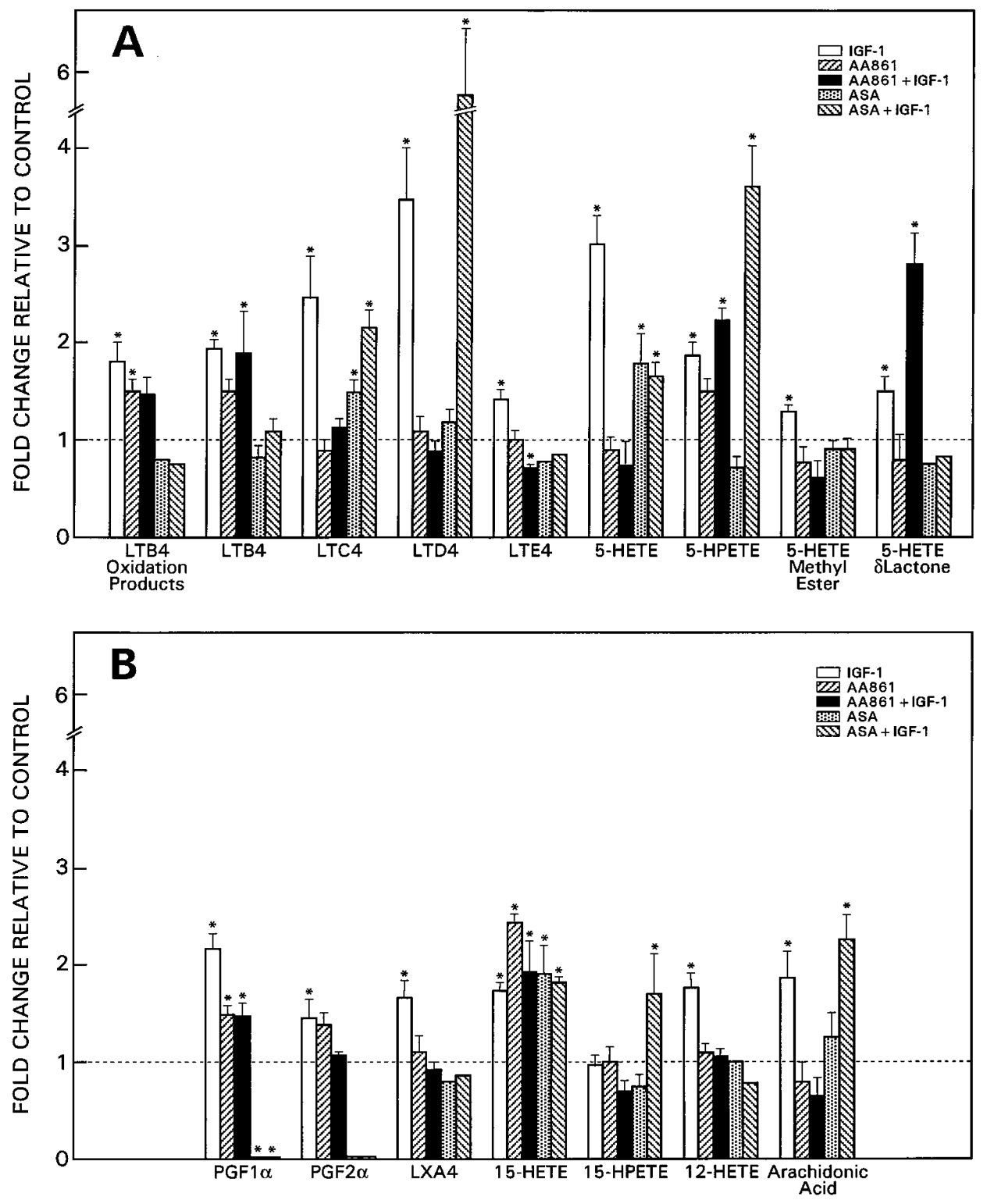

Figure 3. Arachidonate metabolites produced after IGF-I growth factor stimulation in the presence and absence of $10 \mu \mathrm{M}$ AA861 (5-LO) and $30 \mu \mathrm{M}$ ASA (cyclooxygenase inhibitor). The values shown are major measurable products represented as fold increases over control. The data represents the average from three to six experiments and the SEM of the values is shown as error bars, an asterisk indicates that $P<0.05$. The data shown here were obtained at 2 min. Many metabolites are transient but this time period showed maximal production of most metabolites and was representative of the patterns of AA metabolism. (A) 5-lipoxygenase products. (B) Prostanoids and lipoxygenase products.

ASA alone on NCI-H209 cells (Fig. 3, $A$ and $B$ ). Inhibition of cyclooxygenase activity did not result in consistent reduction in lung cancer cell line growth.

Inhibition of the lipoxygenase pathway resulted in greater inhibition of tumor cell line growth. NDGA is a free-radical inhibitor of lipoxygenase activity and has been shown to suppress DNA synthesis in the transformed human monocyte/ macrophage cell line U937 (27). NDGA has been previously shown to inhibit 12-O-tetradecanoylphorbol-13-acetateinduced tumor promotion in a mouse skin carcinogenesis model (28). We observed significant growth inhibition with this compound on all cell lines tested with 5-10 $\mu \mathrm{M}$ (Table I, Fig. $4 B$ ), for both SCLC and NSCLC cell lines.

We next evaluated the proliferative effect of two, more specific 5-LO inhibitors. We observed reproducible growth inhibition compared to vehicle control on all four SCLC and two of three NSCLC cell lines with $\sim 5-10 \mu \mathrm{M}$ AA861 (Table I). This observation complements the biochemical data shown in Fig. 3. Similar results were obtained with the 5-LO inhibitor
MK 886 (3-[1-( $p$-chlorobenzyl)-5-(isopropyl)-3-tert-butylthioindol-2,2-dimethylpropanoic acid) (22), which is a potent and specific inhibitor of leukotriene biosynthesis in intact leukocytes (29). This compound was an effective inhibitor at 5-10 $\mu \mathrm{M}$ concentrations on all cell lines tested. Representative data for three cell lines is shown with AA861 (Fig. 4 C) and MK 886 (Fig. 4 D). A bronchioloalveolar carcinoma, A549, was resistant to AA861, but not to MK 886. MK 886 binds to the membrane-bound FLAP, thus preventing translocation of 5-LO from the cellular cytoplasm (where it is inactive) to the plasma membrane (29). To evaluate the specificity of this compound, we added back 5-HETE to NCI-H209 cells, after growing the cells in $0.6 \mu \mathrm{M}$ MK 886 for $24 \mathrm{~h}$. The addition of $0.005 \mu \mathrm{g} / \mathrm{ml}$ 5 -HETE increased growth by $20 \%$ compared to cells treated identically with the MK 886 but not exposed to 5-HETE. The two inhibitors of the 5-LO pathway block via different mechanisms. The benzoquinone, AA861, was designed to directly inhibit enzymatic activity, but as discussed above also acts via stabilization of some of the hydroperoxy AA derivatives. 

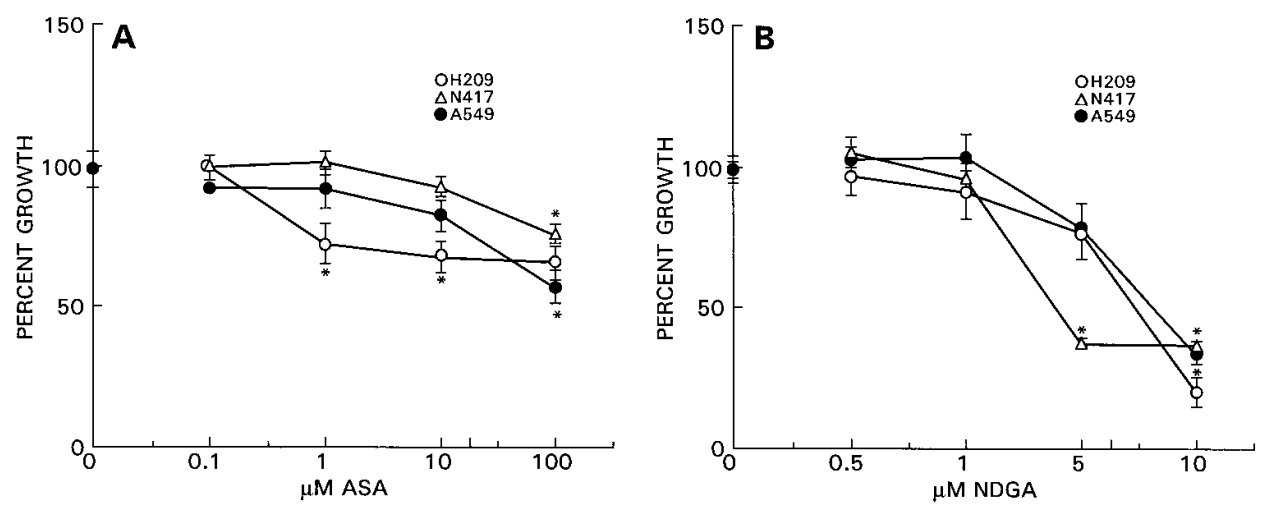

Figure 4. Effect of AA pathway inhibitors on the proliferation of three different lung tumor cell lines. Representative experiments on three different cell lines is shown for each compound. NCI-H209, classic SCLC cell line (open circle), NCI-N417, variant SCLC cell line (open triangle), and A549, NSCLC cell line
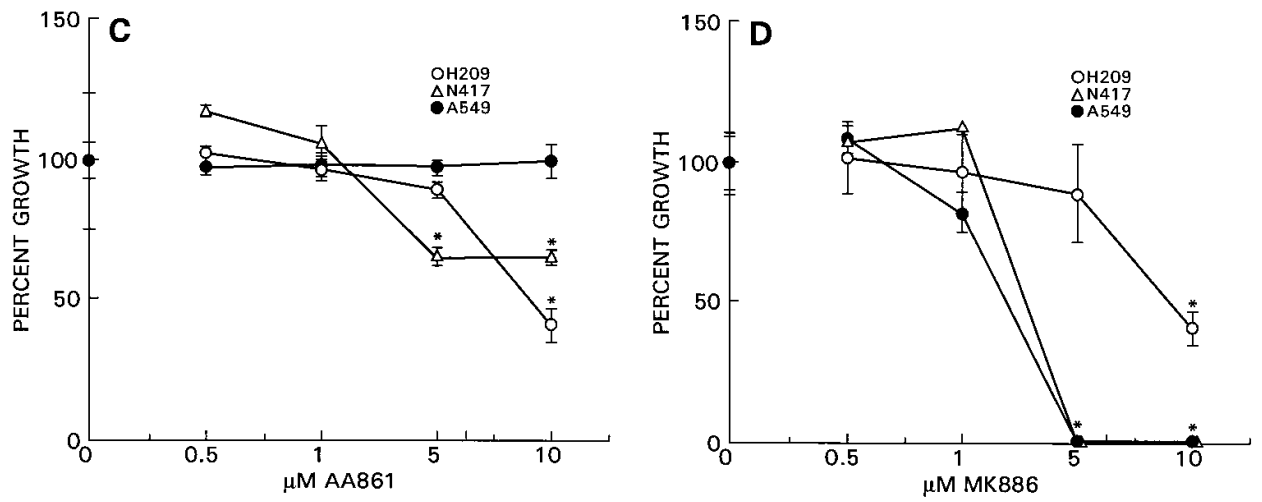

(closed circle). The experimental conditions were as outlined in Methods, and the results are expressed as percent growth $\pm \mathrm{SD}$, with no drug added serving as control and expressed as $100 \%$ growth. Asterisks indicate significant growth inhibition versus control $(P<0.05)$. $(A)$ Dose range concentrations used with ASA were a range of $0.1-100$ $\mu \mathrm{M}$. Concentrations used for $(B)$ NDGA, $(C)$ AA861, and $(D)$ MK 886 were $0.5,1,5$, and $10 \mu \mathrm{M}$ with all three compounds.

Therefore, the 5-LO inhibitor with the most specific mode of action, MK 886 showed the greatest antiproliferative effect. Experiments evaluating $\left[{ }^{35} \mathrm{~S}\right]$ methionine incorporation in cells confirmed that there was no short-term toxicity $(24 \mathrm{~h})$ caused

Table I. Effect of Inhibitors of the AA Metabolism on Growth of Lung Cancer Cell Lines

\begin{tabular}{lcccc}
\hline & \multicolumn{4}{c}{ Inhibitor } \\
\cline { 2 - 5 } Cell Line & $\operatorname{ASA}(100 \mu \mathrm{M})$ & $\mathrm{NDGA}(5 \mu \mathrm{M})$ & AA861 $(10 \mu \mathrm{M})$ & MK $886(5 \mu \mathrm{M})$ \\
\hline \multicolumn{4}{c}{ Percent growth inhibition } \\
SCLC & & & \\
NCI-H209 & $38 \pm 14$ & $75 \pm 12$ & $80 \pm 10$ & $93 \pm 12$ \\
NCI-H345 & $10 \pm 0^{*}$ & $85 \pm 23$ & $94 \pm 9$ & $100 \pm 0$ \\
NCI-H82 & $0 \pm 0^{*}$ & $86 \pm 6$ & $60 \pm 0$ & $100 \pm 0$ \\
NCI-N417 & $10 \pm 0^{*}$ & $87 \pm 6$ & $87 \pm 6$ & $97 \pm 6$ \\
NSCLC & & & & \\
NCI-H1155 & $47 \pm 15$ & $95 \pm 6$ & $68 \pm 27$ & $93 \pm 11$ \\
NCI-H23 & $30 \pm 20$ & $88 \pm 3$ & $60 \pm 10$ & $96 \pm 6$ \\
NCI-A549 & $38 \pm 18$ & $87 \pm 5$ & $0 \pm 0 *$ & $100 \pm 0$ \\
& & & \\
\hline
\end{tabular}

The mean growth inhibition $\pm \mathrm{SD}$ of a minimum of three experiments is presented and was achieved with $100 \mu \mathrm{M}$ for ASA, $10 \mu \mathrm{M}$ for AA861, and $5 \mu \mathrm{M}$ for NDGA and MK 886. For each compound the drug concentration that showed the greatest mean inhibition is shown. All values were determined by assessment of percent growth inhibition calculated from the optical density value, with a minimum of six replicates from at least three different experiments per cell line. Percent growth inhibition compared to vehicle control was significantly different $(P<0.05)$ except where specified. *Indicates no significant difference in growth compared to control. by exposing cell lines to AA861, MK 886, or NDGA (data not shown).

To confirm that lung cancer cell lines express the enzymes which are the targets of the 5-LO and FLAP inhibitors, we analyzed the message expression for 5-LO and FLAP by RTPCR and southern blot analysis. Fig. 5, $A$ and $B$ show that SCLC and NSCLC cell lines tested express both transcripts. Using in situ RT-PCR, we also demonstrate the expression of 5-LO mRNA in paraffin sections taken from primary lung cancer tissue of both SCLC and NSCLC (Fig. 5, $C-F$ ).

In athymic nu/nu mice bearing heterotransplants of the SCLC cell line NCI-H209, the administration of NDGA in their drinking water resulted in significantly smaller xenograft size relative to control. The flank tumor size was an average of $0.77 \mathrm{~cm}^{3}$ for the NDGA treated group and $2.22 \mathrm{~cm}^{3}$ for the placebo group $(P<0.05)$, without any significant difference in total body weight between the two groups. The tumor xenografts were harvested from both groups and examined for the presence of apoptosis-induced oligonucleosomes using a commercially available kit (ApopTag). Tumors from the untreated group of mice had low levels of degraded DNA, whereas the flank tumors harvested from the group of mice treated with NDGA demonstrated a significantly $(P<0.05)$ increased number of cells with apoptotic DNA (Fig. 6), which correlated with the reduction in tumor size. This finding is consistent with other published data (30) and suggests a potential mechanism of growth inhibition mediated by 5-LO inhibition.

\section{Discussion}

Our work demonstrates that the lipoxygenase pathway of AA metabolism is activated in SCLC cells after stimulation by two growth factors. We show that 5-HETE is a major early 5-LO 


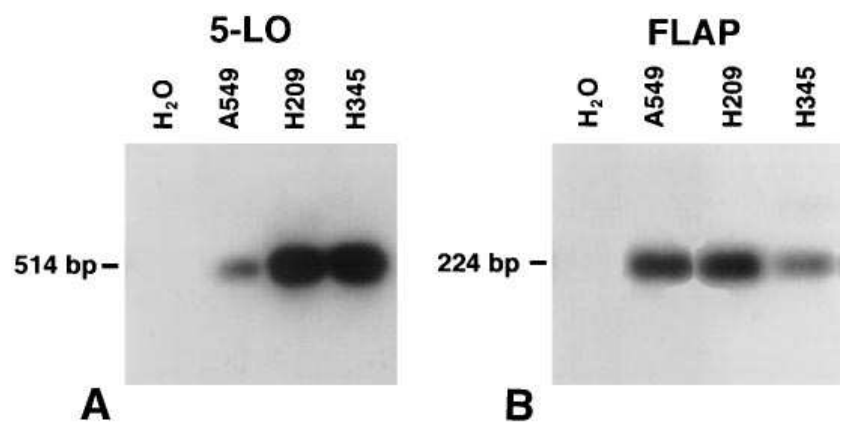

Figure 5. mRNA expression of 5-LO $(A)$ and its associated activating protein $(F L A P)(B)$ in three different cell lines (NCI-H209, NCI-H345, and A549) using RT-PCR. Detection of 5-LO mRNA by in situ RTPCR $(C-F)$, in paraffin sections taken from a SCLC tumor $(C$ and $D)$ and from a NSCLC tumor $(E$ and $F)$. Negative controls $(D$ and $F)$ were performed by substituting the primers with water in the PCR mixture.
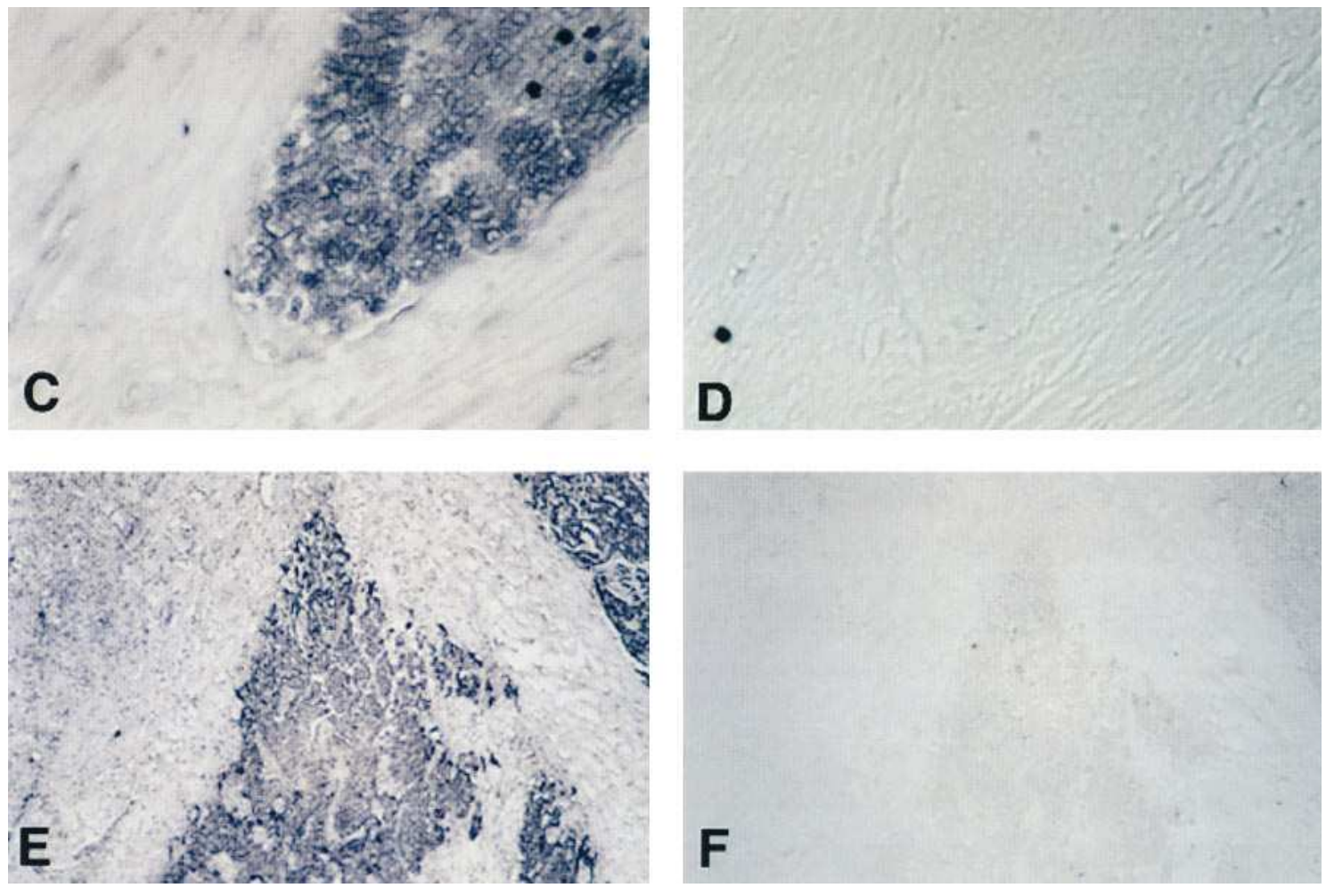

metabolic product of growth factor-stimulated lung tumor cells and that 5-HETE can directly stimulate tumor cell growth in vitro. These cells also produce the specific downstream products of the 5-LO pathway which suggests the presence of bioactive 5-LO enzyme. This study reports for the first time, that the mRNA for the 5-LO and FLAP transcript is expressed in lung tumor cell lines, and we also demonstrate in situ expression of 5-LO message in primary tumor tissue. In addition, HPLC characterization demonstrate that inhibitors of AA metabolism can reverse the production of several metabolites, resulting in inhibition of 5-HETE, LTD4, and AA itself. The inhibition of AA release by a 5-LO inhibitor but not ASA was surprising and suggests a feedback stimulation loop acting via a 5-LO produced metabolite. The increased production of 15HETE, platelet-activating factor, and to some extent prostanoids in the presence of AA861 has been observed in other cell systems in our laboratory. This may indicate a diversion of the arachidonate metabolism to alternative pathways in the presence of an inhibitor when the cells are undergoing continuous stimulation by growth factors.

Furthermore, lung cancer cell growth could selectively be inhibited in vitro by 5-LO inhibitors AA861, MK 886, and
NDGA. The growth inhibition of MK 886 on NCI-H209 could be overcome by the addition of 5-HETE. Although the specificity of the 5-LO inhibitors is not complete, the similar results with the three different types of 5-LO inhibitors is consistent with the lipoxygenase pathway playing a significant role in growth factor signaling. The in vivo experiments with NDGA in athymic nu/nu mice bearing heterotransplants of SCLC cell line NCI-H209, suggests that tumor growth reduction is mediated by apoptotic growth control. In vitro experiments with NCI-H209 also show evidence of increased apoptotic activity in the presence of MK 886 (data not shown).

Inhibitors of AA metabolism can directly or indirectly induce biochemical and morphological changes in cultured cells. In a malignantly transformed prostate cell line, a 5-LO inhibitor caused inhibition of proliferation indicated by modulation of DNA synthesis (31). Specific 5-LO inhibitors have also been shown to have significant antiproliferative effect on several leukemic cell lines but not on HeLa cells (32). Conversely, cysteinyl leukotrienes have been previously reported to increase the growth of normal bronchial epithelial cells (33). Since lung cancer cell growth can be selectively inhibited by 5-LO inhibitors such as AA861, MK 886, and NDGA, further consider- 

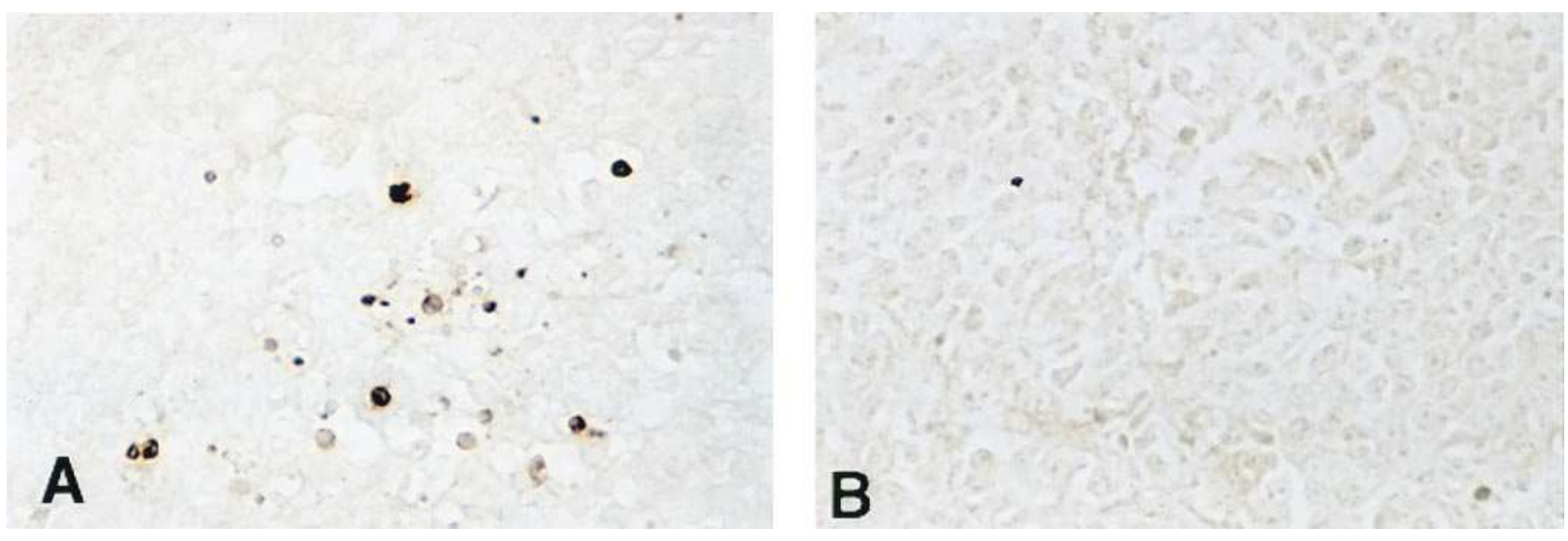

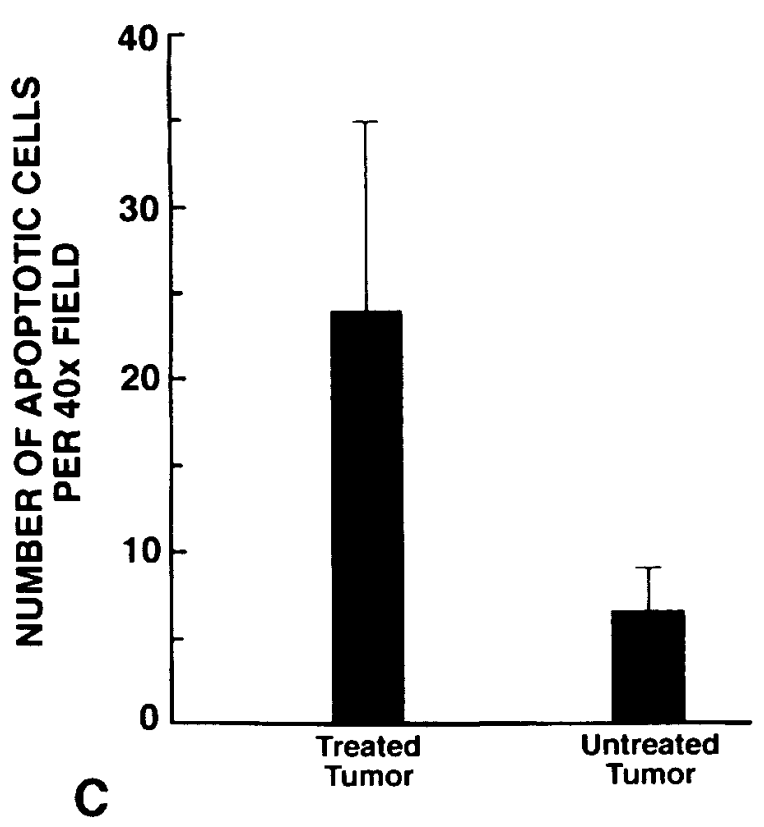

Figure 6. Effect of NDGA administration on apoptosis. Histological sections stained for apoptosis in heterotransplanted tumors of SCLC cell line NCIH209 is shown. (A) Section from a mouse treated with NDGA; $(B)$ section from a mouse in placebo group; $(C)$ statistical analysis of the number of apoptotic cells counted. Data represent the average \pm SD. The difference between the two samples was statistically significant $(P<0.05)$. ation of this approach in advanced stage tumors and early cancer is merited. In our experience, the growth inhibitory effects in vitro of the 5-LO inhibitors is at least as potent as the conventional chemotherapy drugs used for lung cancer treatment (34). Furthermore, the effective drug concentrations needed to inhibit cancer cell line growth with the compounds used in our study are achievable in humans (35). In contrast to the usual toxic chemotherapeutic agents, the modest clinical toxicity of the downstream AA inhibitors make them appropriate for consideration not only for cancer treatment but also for chemopreventive applications. The use of 5-LO inhibitors for lung cancer may complement the proposed use of cyclooxygenase inhibitors to prevent colon cancer $(16,36,37)$.

Growth factors are known to play an important role in the induction and inhibition of apoptosis in several tumor systems (38). The interruption of 5-LO-dependent cell signaling upregulates the rate of apoptotic cell death in a human hematopoietic cell line (31). The same effect has been reported for the cyclooxygenase pathway of AA metabolism in colon cancer (30). Similarly, inhibition of apoptosis has been reported with the progression of a carcinoma in the colon (39). Our results further suggest stimulation of or reestablishment of apoptotic growth regulation resulting from the interruption of the 5-LO pathway, as a possible mechanism for the antiproliferative effect of the lipoxygenase inhibitors. Baserga used the relationship of IGF-I receptor with apoptosis as an example of a growth factor circuit acting as an oncogene, enabling the process of carcinogenesis (20). Our results are consistent with Baserga's hypothesis regarding the critical role growth factor signaling circuits play in permitting cells to cycle through apoptotic growth control. Our data, using cell lines derived from an advanced stage of lung carcinogenesis, suggests that the pathways to reestablish apoptotic growth control are conserved late into the natural history of a cancer.

Understanding of the molecular events involved in growth factor signaling is rapidly evolving. We present our results as a working model for regulation of lung cancer cell growth with potential therapeutic implications. Independent validation of the significance of these observations is desirable since therapeutic efforts currently used in the treatment of lung cancer have not reduced the high mortality rate of this disease $(1,2)$. Lipoxygenase inhibitors represent a new pharmacological tool to renew growth regulation in transformed cell populations. The relationship between tumor growth factor signaling and 
the trophic influence of leukotrienes may also provide a mechanistic link for the clinical association of chronic inflammation, repair of epithelial injury, and the development of cancer. Specifically, antagonizing critical growth factor-dependent signaling pathways may be a fundamental clinical strategy with applicability during all phases of lung carcinogenesis.

\section{Acknowledgments}

We are grateful to R. Murphy, J. Weinstein, J. Battey, and F. Scott for critical reading of the manuscript.

Partial support for this work was provided by the Leila Y. and Harold G. Mathers Charitable Trust.

\section{References}

1. Garfinkel, E., and E. Silverberg. 1990. Lung cancer and smoking trends in the United States over the past 25 years. Ann. NY Acad. Sci. 609:146-154.

2. Shaw, G., and J. Mulshine. 1993. Monoclonal antibodies for early cytologic detection of lung cancer. Seminars in Thoracic and Cardiovascular Surgery. 5:201-209.

3. Cuttitta, F., D. Carney, J. Mulshine, T. Moody, J. Fedorko, A. Fiscler, and J. Minna. 1985. Bombesin-like peptides can function as autocrine growth factors in human small cell lung cancer. Nature (Lond.). 16:823-826.

4. Froesch, E., C. Schmid, J. Schwander, and J. Zapf. 1985. Actions of insulin-like growth factors. Ann. Rev. Physiol. 47:443-467.

5. Nakanishi, Y., J. Mulshine, P. Kasprzyk, R. Natale, R. Maneckjee, I. Avis, A. Treston, A. Gazdar, J. Minna, and F. Cuttitta. 1988. Insulin-like growth factor-1 can stimulate the proliferation of human small cell lung cancer lines. $J$. Clin. Invest. 82:354-359.

6. Siegfried, J., Y.-H. Han, M. DeMichele, J. Hunt, A. Gaither, and F. Cuttitta. 1994. Production of gastrin-releasing peptide by a non-small cell lung carcinoma cell line adapted to serum-free conditions. J. Biol. Chem. 269:85968603.

7. Mulshine, J., A. Treston, F. Scott, I. Avis, C. Boland, R. Phelps, P. Kasprzyk, Y. Nakanishi, and F. Cuttitta. 1992. Lung cancer: rational strategies for early detection and intervention. Oncology. 5:25-32.

8. Sporn, M., and G. Todaro. 1980. Autocrine secretion and malignant transformation. N. Engl. J. Med. 303:878-880.

9. Trepel, J., J. Moyer, F. Cuttitta, H. Frucht, D. Coy, R. Natale, J. Mulshine, R. Jensen, and E. Sausville. 1988. A novel bombesin receptor antagonist inhibits autocrine signals in a small cell lung carcinoma cell line. Biochem. Biophys. Res. Commun. 156:1383-1389.

10. Berridge, M., and R. Irvine. 1989. Inositol phosphates and cell signaling. Nature (Lond). 341:197-205.

11. Millar, J., and E. Rozengurt. 1990. Arachidonic acid release by bombesin. J. Biol. Chem. 265:19973-19979.

12. Sethi, T., S. Langdon, J. Smyth, and E. Rozengurt. 1992. Growth of small cell lung cancer cells: stimulation by multiple neuropeptides and inhibition by broad spectrum antagonists in vitro and in vivo. Cancer Res. 52(Suppl.): 2737s-2742s.

13. Bunn, P.J., D. Dienhart, D. Chan, M. Tagawa, and P. Jewett. 1992. Effects of neuropeptides on human lung and breast cancer cells. J. Natl. Cancer Inst. Monogr. 13:145-151.

14. Axelrod, J., R. Burch, and C. Jelsema. 1988. Receptor-mediated activation of phospholipase A2 via GTP-binding proteins: arachidonic acid and its metabolites as second messengers. Trends Neurosci. 11:117-123.

15. Boyle, T., V. Lancaster, R. Hunt, P. Gemski, and M. Jett. 1994. Method for simultaneous quantitation of platelet activating factor and multiple arachidonate metabolites from small samples: analysis of effects of Staphylococcus aureus enterotoxin B in mice. Anal. Biochem. 216:373-382.

16. Giovannucci, E., K. Egan, D. Hunter, M. Stampfer, G. Golditz, W. Willett, and F. Speizer. 1995. Aspirin and the risk of colorectal cancer in women. $N$. Engl. J. Med. 333:609-614.

17. Henderson, W. 1994. The role of leukotrienes in inflammation. Ann. In- tern. Med. 121:684-697.

18. Batt, D. 1992. 5-lipoxygenase inhibitors and their anti-inflammatory activities. Prog. Med. Chem. 29:1-63.

19. Larsen, J., and E. Acosta. 1993. Leukotrine-receptor antagonists and 5-lipoxygenase inhibitors in asthma. Ann. Pharmacother. 27:898-903.

20. Baserga, R. 1994. Oncogenes and the strategy of growth factors. Cell. 79:927-930.

21. Beaven, M., J. Moore, G. Smith, T. Hesketh, and J. Metcalfe. 1984. The calcium signal and phosphatidylinositol breakdown in $2 \mathrm{H} 3$ cells. J. Biol. Chem. 259:7137-7142.

22. Gillard, J., A. Ford-Hutchinson, C. Chan, S. Charleson, D. Denis, A. Foster, R. Fortin, S. Leger, C. McFarlane, H. Morton, et al. 1989. L-663,536(MK886) (3-[-(4-chlorobenzyl)-3-t-butyl-thio-5-isopropylindol-2-yl]-2,2-dimethylpropaoic acid), a novel, orally active leukotriene biosynthesis inhibitor. Can. $J$. Physiol. Pharmacol. 67:456-464.

23. Nakanishi, Y., F. Cuttitta, P. Kasprzyk, I. Avis, S. Steinberg, A. Gazdar, and J. Mulshine. 1988. Growth factor effects on small cell lung cancer using a colorimetric assay: can a transferrin-like growth factor mediate autocrine growth? Exp. Cell Biol. 56:74-85.

24. Davis, L., M. Dibner, and J. Battey. 1986. Basic Methods in Molecular Biology. Appleton and Lange, East Norwalk, CT. 62-65.

25. Martinez, A., M.-J. Miller, K. Quinn, E. Unsworth, M. Ebina, and F. Cuttitta. 1995. Non-radioactive localization of nucleic acids by direct in situ RTPCR in paraffin-embedded sections. J. Histochem. Cytochem. 43:739-747.

26. Furukawa, M., T. Yoshimoto, K. Ochi, and S. Yamamoto. 1984. Studies on arachidonate 5-lipoxygenase of rat basophilic leukemia cells. Biochim. Biophys. Acta. 795:458-465.

27. Ondrey, F., J. Harris, and K. Anderson. 1989. Inhibition of U937 eicosanoid and DNA synthesis by 5,8,11,14-eicosatetraynoic acid, an inhibitor of arachidonic acid metabolism and its partial reversal by leukotriene C4. Cancer Res. 49:1138-1142.

28. Yamamoto, S., and R. Kato. 1992. Inhibitors of the arachidonic acid cascade and their chemoprevention of skin cancer. In Cancer Chemoprevention. L. Wattenberg, M. Lipkin, C. Boone. and G. Kelloff, editors. CRC Press Inc. Boca Rotan, FL. 141-151.

29. Rouzer, C., A. Ford-Hutchinson, H. Morton, and J. Gillard. 1990 MK886, a potent and specific leukotriene biosynthesis inhibitor blocks and reverses the membrane association of 5-lipoxygenase in ionophore-challenged leukocytes. J. Biol. Chem. 265:1436-1442.

30. Piazza, G., A. Rahm, M. Krutzsch, G. Sperl, N. Paranka, P. Gross, K. Brendel, R. Burt, D. Alberts, R. Pamukcu, and D. Ahnen. 1995. Antineoplastic drugs Sulindac Sulfide and Sulfone inhibit cell growth by inducing apoptosis. Cancer Res. 55:3110-3116.

31. Anderson, K., T. Seed, F. Ondrey, and J. Harris. 1994. The selective 5-lipoxygenase inhibitor A63162 reduces PC3 proliferation and initiates morphologic changes consistent with secretion. Anticancer Res. 14:1951-1960

32. Tsukada, T., K. Nakashima, and S. Shirakawa. 1986. Arachidonic 5-lipoxygenase inhibitors show potent antiproliferative effects on human leukemic cell lines. Biochem. Biophys. Res. Commun. 140:812-816.

33. Leikauf, G., H.-E. Claesson, C. Doupnik, S. Hybbinette, and R. Grafstrom. 1990. Cysteinyl leukotrienes enhance growth of human airway epithelia cells. Am. J. Physiol. 259:L255-L261.

34. Shaw, G., A. Gazdar, R. Phelps, R. Linnoila, D. Ihde, B. Johnson, H. Oie, H. Pass, S. Steinberg, B. Gosh, et al. 1993. Individualized chemotherapy for patients with non-small cell lung cancer determined by prospective identification of neuroendocrine markers and in vitro drug sensitivity testing. Cancer Res. 53 : 5181-5187.

35. Tagari, P., C. Brideau, C. Chan, R. Frenette, and C. Black. 1993. Assessment of the in vivo biochemical efficacy of orally active leukotrine biosynthesis inhibitors. Agents Actions. 40:62-71.

36. Thun, M., M. Nambodiri, and C. H. Heath Jr. 1991. Aspirin use and reduced risk of fatal colon cancer. N. Engl. J. Med. 325:1593-1596.

37. Giovannucci, E., E. Rimm, M. Stampler, G. Colditz, A. Ascherio, and W. Willett. 1994. Aspirin use and the risk for colorectal cancer and adenoma in male health professionals. Ann. Intern. Med. 121:241-246.

38. Thompson, C. 1995. Apoptosis in the pathogenesis and treatment of disease. Science (Wash. DC). 267:1456-1462.

39. Bedi, A., P. Pasricha, A. Akhtar, J. Barber, G. Bedi, F. Giardiello, B. Zehnbauer, S. Hamilton, and R. Jones. 1995. Inhibition of apoptosis during development of colorectal cancer. Cancer Res. 55:1811-1816. 